\title{
TRABALHO E EDUCAÇÃO NO PENSAMENTO (NEO)LIBERAL E HISTÓRICO- CRÍTICO: FUNDAMENTOS PARA PENSAR A REFORMA CURRICULAR NO ENSINO MÉDIO
}

\author{
Carlos Soares Barbosa*
}

\begin{abstract}
Resumo: O presente artigo tem o objetivo de identificar os principais aspectos de duas propostas para a formação das classes trabalhadoras, radicalmente opostas teórica e metodologicamente. De um lado, a matriz (neo)liberal, baseada nas idéias de Adam Smith e Friedrich Hayek; do outro, a matriz histórico-crítico, fundamentada nas idéias de Karl Marx e Antonio Gramsci. Trata-se de pesquisa histórica e bibliográfica, com o propósito de demonstrar o conservadorismo do discurso do governo Temer, que tenta apresentar como "novo" as mudanças efetuadas no Ensino Médio, por meio da Lei $n^{\circ}$ 13.415/2017. O estudo demonstra que o novo desenho curricular atende a interesses antigos: o de reforçar a histórica dualidade estrutural do ensino brasileiro, retomando a formação instrumental e fragmentada proposta na Lei $n^{\circ} 5692 / 71$, do período da ditadura civilmilitar, e no Decreto $n^{\circ}$ 2208/97, editado no governo de Fernando Henrique Cardoso. Conclui que, com a retomada da agenda neoliberal, os planejadores da reforma buscam adequar o Ensino Médio as demandas econômicas e de mercado, abandonando o projeto de formação humana e integral, defendido pelos teóricos da matriz histórico-social e presente nas Diretrizes Curriculares Nacionais para o Ensino Médio, de 2012. Além de abandonar os objetivos previstos na LDB (1996) para o Ensino Médio, entre eles, desenvolver a autonomia intelectual e o pensamento crítico dos estudantes, por meio da articulação teoria e prática.
\end{abstract}

Palavras-chaves: Trabalho. Educação. Neoliberalismo. Teoria Histórico-Social. Ensino Médio.

\section{Introdução}

Em tempos de retomada do desmanche neoliberal no Brasil, após o golpe institucional, jurídico e midiático ocorrido em abril de 2016 e que se expressa nas reformas em curso, entre elas, a reforma do Ensino Médio, faz-se necessário refletir sobre os pilares do pensamento (neo)liberal e do pensamento histórico-crítico com o propósito de fornecer subsídios teóricos para os que se encontram na luta contra a redução do Estado em setores importantes da vida coletiva e

\footnotetext{
* Professor Adjunto da Faculdade de Educação da Universidade do Estado do Rio de Janeiro (UERJ), Campus Maracanã. Historiador, Doutor em Políticas Públicas e Formação Humana (PPFH/UERJ) e Mestre em Educação (UFRJ). Pesquisador das áreas de Trabalho e Educação e Educação de Jovens e Adultos.
} 
a perpetuação das desigualdades sociais. A reflexão aqui proposta é referenciada teórica e metodologicamente no método do materialismo histórico e dialético e justifica-se no entendimento de que o domínio da teoria contribui para a compreensão para além da aparência dos fenômenos sociais, com vistas à transformação da realidade; o que só ocorre na ação, na práxis, uma vez que a atividade teórica, per si, não é capaz de realizar.

Como toda política, a atual proposta curricular do Ensino Médio - exarada inicialmente por meio da Medida Provisória de $\mathrm{n}^{\mathrm{o}} 746$ de julho de 2016, e posteriormente transformada na Lei n $13.415 / 2017$ - tem sido alvo de disputa e tem recebido intensas críticas por parte dos estudiosos de diversas linhas no campo da educação, entre eles, de "Trabalho e Educação". Principalmente, devido ao explícito alinhamento da proposta de formação de trabalhadores de "novo tipo" demandados na atual configuração do sistema capitalista (KUENZER, 2017; MOTTA, FRIGOTTO, 2017), conformados as diversas formas de relações de trabalho precarizado, a exemplo da terceirização, da subcontratação e do "part-time. Neste sentido, partimos da premissa que a leitura dos teóricos clássicos nos auxilia a demonstrar o conservadorismo do discurso governamental, veiculado nos principais aparelhos midiáticos do país com o intuito de conquistar o consentimento passivo/ativo da maioria da população para os projetos reformistas em execução, que tenta apresentar como "novo" as mudanças efetuadas no Ensino Médio. O estudo dos fundamentos teóricos do pensamento (neo)liberal demonstra que, na prática, o novo desenho curricular atende a interesses antigos: o de reforçar a histórica dualidade estrutural do ensino brasileiro, retomando a formação instrumental e fragmentada implementada durante os governos civil-militar, por meio da Lei n. 5692/71, e no governo de Fernando Henrique Cardoso, com o Decreto n.2208/97. Ao separar a formação propedêutica da formação profissional inviabiliza a possibilidade de se promover a formação integral das classes trabalhadoras, projeto defendido pelos teóricos da matriz histórico-social e que fora retomado nos governos Lula da Silva e Dilma Roussef, apesar de alguns equívocos (FERREIRA, 2017).

Visando a contribuir com as reflexões desencadeadas neste contexto de contrarreformas, tendo em vista os ataques aos direitos sociais conquistados no período reformista (COUTINHO, 2012), o presente artigo tem o objetivo de identificar os principais aspectos de duas propostas radicalmente opostas para a formação das classes trabalhadoras: de um lado, a matriz 
liberal/neoliberal, que fundamenta o vigente projeto reformista; e, do outro, a teoria históricocrítica, que fundamenta a proposta de formação integral. Para a realização de tal objetivo, a primeira sessão do texto apresenta a diferente compreensão que os teóricos de ambas as matrizes possuem sobre o conceito de trabalho, ancorados especialmente nas ideias de Adam Smith, Friedrich Hayek, Karl Marx e Antonio Gramsci, respectivamente, a fim de realizar, na sessão seguinte, a articulação entre essas concepções e as propostas educacionais defendidas por eles. A parte final do texto reserva-se a uma breve análise da reforma do Ensino Médio a fim de demonstrar o retrocesso que ela representa.

\section{A concepção de trabalho no pensamento liberal}

Embora a ordem política liberal tenha iniciado na Inglaterra no final do século XVII, foi somente no final do século seguinte que ela foi sistematizada teoricamente, tendo como principais representantes David Hume, Adam Smith, Ricardo, Edmundo Burke, T. B. Macaulay, Stuart-Mill e Iorde Acton, na Inglaterra; Tocqueville e Benjamin Constant, na França; Immanuel Kant e Wilhelm Von Humboldt, na Alemanha, bem como James Madison, John Marshall e Daniel Webster, nos Estados Unidos. A formulação teórica do liberalismo ocorreu em um contexto marcado por profundas transformações de cunho capitalista, uma vez que as doutrinas mercantilistas que defendiam o Estado forte e intervencionista na economia já não eram consideradas as mais ideais para a produção material da riqueza da Nação.

A tese central do livro "A Riqueza das Nações", escrito por Adam Smith, em 1776, consiste de que a riqueza é produto do trabalho humano. Na concepção do referido teórico o verdadeiro papel do capital seria aumentar a produtividade do trabalho, o que ocorreria com a conjugação de dois elementos: o uso de máquinas, "que facilitam e abreviam o trabalho possibilitando a uma única pessoa fazer o trabalho que, de outra forma, teria que ser feito por muitas" (SMITH, 1985, p.43), e a divisão do trabalho, que promove o aumento da habilidade dos trabalhadores (especialização) e a redução do tempo da produção, dada a poupança do tempo que seria costume o trabalhador perder ao passar de um tipo de trabalho para o outro.

Smith argumenta que a divisão do trabalho é a fonte da riqueza das Nações por proporcionar um espiral do crescimento econômico, que funcionaria da seguinte forma: com o 
crescimento da produtividade do trabalho há o aumento do capital excedente sobre os salários. Este capital excedente (lucro) é reaplicado no setor produtivo, que gera o aumento da produção e, consequentemente, uma demanda por mão de obra sobre o mercado de trabalho, ocasionando um crescimento concomitante dos salários e a melhora das condições de vida da população. $\mathrm{O}$ aumento paralelo do emprego, salários e população amplia o tamanho dos mercados, dando início ao espiral ascendente e interminável de progresso (HUNT; SHERMAN, 1991).

De acordo com esta teoria, o empresário-capitalista ao agir em benefício de seu interesse age em prol da sociedade, sendo, por essa razão, fundamental que tenha liberdade para agir inspirado em seus próprios interesses (ordem natural). Para os teóricos liberais não é a intervenção do Estado na economia que assegura a prosperidade das Nações, mas essa ordenação natural, ancorada na competição, no mercado livre e na complementaridade de interesses entre capital e trabalho, pois, da mesma forma que os produtores precisam aprimorar a qualidade do seu produto para disputar a preferência dos consumidores, capital e trabalho para se manterem na competição teriam de ser investidos da forma mais produtiva. Ambos sairiam ganhando por força do próprio mercado (HUNT; SHERMAN, 1991).

Considerando a igualdade de condições entre capital e trabalho, na concepção de Smith o mercado agiria “como uma "mão invisível”, canalizando as motivações egoístas e interesseiras dos homens para atividades mutuamente complementares, que promoveriam de forma harmoniosa o bem-estar de toda a sociedade. Hayek, no século XX, também compartilha da ideia da suposta satisfação de interesses múltiplos e não conflitantes no mercado. Para ele, o livre mercado é um mecanismo regulador, porque há uma propensão dos indivíduos em trocar, levando-o a acreditar que "até mesmo no pior dos tempos, algo como nove entre dez pessoas terão as suas expectativas confirmadas (HAYEK apud MÉSZAROS, 2002, p. 922). A crença na igualdade de troca entre os indivíduos é um dos pilares do pensamento liberal. De acordo com Smith,

cada trabalhador tem para vender uma grande quantidade do seu próprio trabalho, além daquela que ele mesmo necessita; e pelo fato de todos os outros trabalhadores estarem exatamente na mesma situação, pode ele trocar grande parte de seus próprios bens por uma grande quantidade, ou - o que é a mesma coisa - pelo preço da grande quantidade de bens desses outros. Fornece-lhes em abundância aquilo que carecem, e estes, por sua vez, com a mesma abundância, lhe fornecem aquilo de que ele necessita. Assim é que em todas as camadas da sociedade se difunde uma abundância geral dos bens (SMITH, 1985, p. 45/46). 
A “ordem espontânea do mercado" repousa na reciprocidade, isto é, na conciliação de diferentes objetivos para o benefício mútuo dos participantes (HAYEK, 1998). Trata-se de uma sociedade feitichizada, onde todos possuem igualdade de chances e oportunidades, independentemente das diferenças de talentos e ocupações entre os indivíduos. Não há antagonismo, mas harmonia econômica entre os interesses individuais e coletivos.

Decorre daí a valorização do individualismo pelos teóricos liberais, sem se preocuparem com o coletivo e se colocarem contrários a constituição de um Estado que busque promover a justiça social, já que para eles existe apenas a justiça de conduta individual. Não é por acaso que para Hayek as atividades coercitivas do Estado deveriam limitar-se apenas à aplicação de regras de conduta justa, visto que a justiça social ou distributiva é uma ilusão que não pode ser atingida.

Em resposta as reflexões de Smith, Marx direciona sua análise por meio da compreensão materialista da realidade capitalista, se opondo frontalmente ao pensamento dos liberais.

\section{A concepção de trabalho na teoria histórico-social}

Para Marx, o trabalho é atividade essencialmente humana, uma vez que é por meio do trabalho que os homens projetam ou modificam suas condições de vida. Por meio da relação recíproca e dialética que estabelecem com a natureza e com outros seres humanos criam e recriam, pela ação consciente do trabalho, sua própria existência. Trata-se da dimensão ontológica do trabalho; dimensão criadora do ser social, da vida humana (LUKÁCS, 2012).

O trabalho é categoria central na teoria marxista por ser a condição natural e eterna da produção da vida social. É por meio do trabalho que Marx fundamenta o processo de constituição do homem, assumindo duas dimensões distintas e sempre articuladas: trabalho como mundo da necessidade e trabalho como mundo da liberdade. Assim, ao mesmo tempo em que se constitui no sistema capitalista como reino da servidão e desumanização, também pode vir a se constituir como reino da emancipação e criação (FRIGOTTO, 2005). Desta forma, por analisar o caráter histórico do trabalho, Marx dedicou grande parte de sua vida a denunciar as perversidades do sistema capitalista que deslocou o trabalho para além dos limites de suas necessidades naturais. 
Como demonstra referido teórico, desde sua origem a formação da sociedade capitalista é marcada pela desigualdade social e pela contradição entre capital e trabalho, uma vez que a divisão do trabalho efetuada para agilizar o processo da produção significou não só a expropriação dos trabalhadores dos meios de produção, mas também de seu saber, que passaram a ser apropriados e controlados pelo capitalista. Neste sentido, a divisão do trabalho é também a expressão da existência de diferentes formas de propriedade, pois implica a separação básica entre os instrumentos para o trabalho, de um lado, e o próprio trabalho, de outro.

A divisão do trabalho e a introdução de novas máquinas, portanto, conduziram a uma nova racionalidade de produção e o estabelecimento de novas relações de trabalho - o trabalho assalariado -, em que o trabalhador deixa de produzir para satisfação de suas necessidades e passa a produzir para satisfação das necessidades de outrem. Não é mais a necessidade do trabalhador que orientará a relação homem-natureza, tornando o homem e a natureza em recursos para fins de acumulação de capital.

A passagem do trabalho enquanto satisfação da necessidade para o de acumulação de capital constitui, para Marx, na transformação do trabalho objetivado, concreto e real (produtor de valor de uso) em trabalho abstrato e geral (produtor de valor de troca). Ou seja, constitui a passagem para o trabalho alienado, uma vez que o homem trabalha não mais para satisfazer suas necessidades, mas para produzir mercadorias para serem trocadas. Produção e consumo se tornam a tônica do novo modo de produção, pois a produção de excedente requer necessariamente a construção de uma sociedade de consumo, estimulando crescentemente a criação de falsas necessidades. Como denuncia Marx (1978, p. 18): “o trabalhador só deve ter o suficiente para querer viver e só deve querer viver para ter".

E como o trabalhador transfere a outrem o seu direito de propriedade, o formato que o trabalho possui no capitalismo é o de trabalho alienado, adquirindo a forma de auto-sacrifício, por se dar conta o trabalhador de que quando está no trabalho não é dono de si mesmo, mas pertence a outro. Desse modo, o trabalho deixa de ser percebido como "condição natural da existência humana, condição do metabolismo entre homem e natureza, independentemente de qualquer forma social" (MARX, 1978, p.142), e passa a ser visto pelo trabalhador como algo degradante, por ser algo fora de si. Subjetivamente, o trabalho abstrato transformado em alienado 
é percebido pelo homem como algo que o desumaniza, que lhe faz desgraçado e infeliz, pois não mais se reconhece nas obras que ele produz. Sua atividade criativa, em vez de enriquecer a sua existência só faz reforçar e ampliar o poder material que o domina. Sob o regime de alienação, o trabalho transforma-se em um simples meio de conservação de sua existência física. Desse modo,

\footnotetext{
chega-se ao resultado de que o homem, (o trabalhador) só se sente agir livremente somente nas suas funções animais: comer, beber e procriar, ou ainda, quando muito, na escolha de sua casa, de seu vestuário etc., em compensação, ele se sente animal em suas funções propriamente humanas. O que é animal torna-se humano, e o que é humano, torna-se animal (MARX, apud HUNT; SHERMAN, 1991, p.96).
}

Entretanto, ao mesmo tempo em que o trabalho se constitui no sistema capitalista como reino da servidão e desumanização, ele pode vir a se constituir também como reino da emancipação e criação. Para isso faz-se necessária à superação da alienação, na qual a educação tem muito a contribuir, tornando o trabalho um princípio educativo.

Para ambas matrizes a educação tem um papel primordial. Enquanto para os liberais ela é um importante instrumento de manutenção da sociedade, para a matriz histórico-crítica a educação constitui-se em importante instrumento para a superação da falsa consciência e a transformação social.

\section{A educação na matriz (neo)liberal}

Para Smith, além do aumento da produtividade, há outra vantagem da divisão do trabalho e a conseqüente repetição mecânica (especialização) do trabalhador em determinada tarefa: a dispensa do trabalhador do ato de pensar para executá-la. Esta divisão, portanto, pressupõe a existência de dois grupos de trabalhadores: os que pensam, planejam e elaboram o trabalho, e aqueles que o executam. Pressupõe a divisão entre trabalho intelectual e trabalho manual.

Tal fragmentação no mundo do trabalho irá se refletir na esfera educacional com a formação de uma educação dual, diferenciada de acordo com a classe social. Para as classes dominantes e dirigentes uma formação que pode se estender a níveis superiores; para os trabalhadores, rudimentos do ler e escrever e encaminhamento para a profissionalização.

Entretanto, no final do século XVIII Smith não estabelecia um vínculo direto entre educação e qualificação profissional como meio de garantir maiores níveis de desempenho e de 
produtividade. Para ele, a educação serviria para o disciplinamento do trabalhador a ordem econômico-social que se consolidava, pois "um povo instruído e inteligente sempre é mais decente e ordeiro do que um povo ignorante e obtuso" (SMITH, 1985, p.217).

Assim, se o trabalho era a fonte da riqueza material das Nações, a educação para Smith era o meio necessário para o disciplinamento do trabalhador, o que seria possibilitado com a superação do emprobrecimento cultural, fruto da própria divisão do trabalho. Afinal,

com o avanço da divisão do trabalho, a ocupação da maior parte daqueles que vivem do
trabalho, isto é, da maioria da população, acaba restringindo-se algumas operações
extremamente simples, muitas vezes a uma ou duas [...] O homem que gasta toda sua
vida executando algumas operações simples [...] não tem nenhuma oportunidade para
exercitar sua compreensão ou para exercer seu espírito inventivo no sentido de
encontrar meios para eliminar dificuldades que nunca ocorrem [...] tornando-se
geralmente tão embotado e ignorante quanto o possa ser uma criatura humana [...]
incapaz de conceber algum sentimento generoso, de formar algum julgamento justo [...]
incapaz de formar juízo sobre os grandes e vastos interesses de seu país (SMITH, 1985,
p. 213).

Esta é a principal razão da educação, posto que, tornado o homem embotado e ignorante, o empobrecimento cultural colocaria em risco o estabelecimento de comportamentos adequados à vida no ambiente fabril e na sociedade em geral. Portanto, em uma sociedade civilizada o Estado deveria dar maior atenção à educação das pessoas comuns. Ainda segundo o autor,

embora as pessoas comuns não possam [...] ser tão bem instruídas [...] podem aprender as matérias mais essenciais da educação - ler, escrever e calcular [...] - O Estado pode facilitar, encorajar e até mesmo impor a quase toda a população a necessidade de aprender os pontos mais essenciais da educação (SMITH, 1985, p. 215).

A educação da classe trabalhadora, no entanto, deveria ser em "doses homeopáticas”, isto é, a mínima necessária para que não colocasse em risco a ordem econômico-social, já que a desqualificação do trabalho é um processo inexorável inerente ao capitalismo. Refletindo a ideologia política da burguesia dos séculos XVII e XVIII, o liberalismo clássico preconiza a igualdade dos homens frente à lei e às oportunidades de sucesso profissional. Nesta ótica, o fracasso advém da falta de esforço, ignorância ou de talento do indivíduo em uma sociedade concebida como harmônica. E sendo a diferença de talentos útil para a sociedade, cabe a escola revelar e desenvolver em cada indivíduo suas aptidões, talentos e vocações inatas, pois é a partir delas que ele irá adquirir sua posição na sociedade. O sucesso é uma questão de mérito, pois como afirma Hayek (1998, p.51), os membros da sociedade "têm oportunidade de usar com 
sucesso seu conhecimento individual para a consecução dos próprios objetivos individuais.” A hierarquização social é justificada com base no mérito individual, sendo a ascensão social condicionada à educação e ao nível de instrução.

Esta concepção esconde a essência da sociedade capitalista - a desigualdade social advinda do conflito de interesses entre capital e trabalho - e, paradoxalmente, responsabiliza as maiores vítimas do sistema pelas suas próprias mazelas. Nesta perspectiva, a finalidade da educação dual defendida pelos teóricos (neo)liberais é a reprodução das forças produtivas e das relações de produção. Para isso, não só mascara a realidade, como internaliza nos indivíduos os valores do sistema de capital a fim de criar um consenso, levando-os a defender como seus os interesses do capital (MÉSZAROS, 2005). Esta internalização, segundo Aranha (1989), ocorre por meio da naturalização, quando se supõe que os fatos façam parte da natureza das coisas e não enquanto resultado da ação humana; da inversão, quando é colocada como causa o que na verdade é efeito; e da abstração, quando trata as questões de forma abstrata, sem examinar a situação histórica concreta.

É contra esta concepção de educação que Marx e Gramsci vão direcionar suas críticas, propondo uma formação que visa à superação da exploração do trabalho e à emancipação humana.

\section{A educação na teoria histórico-social}

O objetivo de Marx consiste em explicitar as contradições do sistema capitalista, ressaltando o conflito de interesses entre capital e trabalho, com vista a sua superação. Para isso, ao contrário de uma educação unilateral, preocupada apenas com a especialização da mão-deobra para o mercado de trabalho e a transmissão de valores que legitimam a manutenção da ordem capitalista, Marx (1978) e Gramsci (1995) concebem uma educação que rompa a separação entre trabalho manual e intelectual, isto é, voltada para a formação de homens completos, que trabalham "não só com as mãos, mas com o cérebro, e que consciente do processo que desenvolve, domina-o e não é por ele dominado" (MANACORDA, 1991, p.95).

O constructo do homem fragmentado se dá com a expansão da escola para as classes trabalhadoras, após a revolução industrial. O que se verificou a partir de então foi a estruturação 
de um sistema dual de ensino, reproduzindo a divisão social do trabalho. De um lado, a escola da classe dominante (acentuadamente livresca) e, do outro, a escola do trabalhador (acentuadamente profissional e prática). Duas formações completamente distintas que não compartilham princípios, conteúdos e métodos. Contra a esta unilateralidade, Marx concebe uma educação cujo conteúdo e método fundamenta-se na união entre ciência, trabalho e ensino tecnológico (teórico e prático).

Marx identifica o trabalho como parte relevante do processo educativo para fins da emancipação humana; no entanto, essa libertação e as transformações sociais serão mais eficazes caso o trabalho se constitua em um princípio educativo e não um mero recurso didático. Nessa mesma perspectiva, Gramsci critica que, com o desenvolvimento da base industrial a tendência do sistema de ensino italiano foi

\footnotetext{
abolir qualquer tipo de escola "desinteressada" (não imediatamente interessada) e "formativa", ou conservar delas tão-somente um reduzido exemplar destinado a uma pequena elite que não deve pensar em se preparar para um futuro profissional, bem como a de difundir cada vez mais as escolas profissionais especializadas, nas quais o destino do aluno e sua futura atividade são predestinados (GRAMSCI, 1995, p.118).
}

Para Marx e Gramsci, a escola instrumental, especializada e tecnicista defendida pelos liberais é uma escola discriminatória, pois sendo comprometida com a conservação do sistema capitalista reforça e perpetua as desigualdades sociais. Daí Gramsci considerar um processo de profunda degenerescência o fato de as escolas de tipo profissional tomar a frente da escola formativa. E acrescenta, "o aspecto mais paradoxal reside em que este novo tipo de escola aparece e é louvada como democrática, quando, na realidade, não só é destinada a perpetuar as diferenças sociais, como ainda a cristalizá-las” (GRAMSCI, 1995, p. 136). Por isso considera nada democrático a processo de proliferação das escolas profissionais.

Assim, em vez do utilitarismo que visa apenas à formação rápida de mão-de-obra minimamente qualificada para o trabalho técnico, para Gramsci a escola das classes trabalhadoras deve potencializar todas as dimensões humanas. Defende uma escola que vise à maturidade e autonomia intelectual do aluno, potencializando a sua dimensão criadora e criativa, sem tratá-lo como um recipiente passivo e mecânico. Uma escola unitária,

de formação humanista (entendido o termo "humanismo" em sentido amplo) ou de cultura geral que deveria se propor a tarefa de inserir os jovens na atividade social, depois de tê-lo levado a um certo grau de maturidade e capacidade, à criação intelectual e prática e a uma certa autonomia na orientação e iniciativa (GRAMSCI, 1995, p.121) . 
Ao defender a formação geral Gramsci não se descompromete com o desenvolvimento científico e tecnológico; pelo contrário, sua tese é de que o trabalho deve ser o princípio educativo da ação pedagógica. Desse modo, a escola unitária é a escola que integra trabalho intelectual e manual (técnico, industrial) com o objetivo de "introduzir na vida social os jovens, dotados de certa autonomia intelectual e de uma capacidade de criação intelectual e prática, e de orientação independente" (MANACORDA, 1990, p. 158). Trata-se de uma escola que não esteja voltada apenas aos interesses do mercado, mas em desenvolver um processo de busca com fins à superação da alienação do trabalho através de sua ação política, ao assegurar a autoformação e valorizar o conhecimento do estudante, integrando-o ao processo pedagógico. Uma formação assentada na concepção de que as relações de trabalho são também relações pedagógicas, e que, para tanto, devem se basear na cooperação, no coletivismo e na solidariedade e não na competitividade e no individualismo.

Para o referido teórico italiano, a escola tradicional era oligárquica não pelo seu método de ensino, mas porque estava reservada apenas a uma elite de futuros dirigentes. Por isso,

se quisermos romper essa trama será necessário, não multiplicar e graduar os tipos de escola profissional, mas criar o tipo único de escola preparatória (elementar-média) que conduza o jovem até o limiar da escolha profissional, formando-o, nesse meio tempo, como um homem capaz de pensar, de estudar, de dirigir, ou de controlar quem dirige (GRAMSCI, 1995, p.136).

Concebendo a importância política da escola para a classe trabalhadora, Gramsci defende a universalização da educação escolar e rejeita o espontaneísmo que se traduz no abandono do jovem aos influxos casuais do ambiente, na renúncia de educar. Assim como Marx, para ele a escola das classes subalternas deve ser de noções rigorosas, pois o saber e a cultura não devem ser exclusivos das classes dominantes e dirigentes. Para isso, faz-se necessário uma severidade pedagógica nos primeiros anos de idade. Esta pedagogia da exigência se justifica a fim de

\footnotetext{
convencer a muita gente que o estudo é também um trabalho, não só muscular-nervoso mas intelectual; é um processo de adaptação, é um hábito adquirido com esforço, aborrecimento e mesmo sofrimento. A participação das mais amplas massas na escola média leva consigo a tendência a afrouxar a disciplina do estudo, a provocar "facilidades". Muitos pensam, inclusive, que as dificuldades são artificiais, já que estão habituados a só considerar como trabalho e fadiga o trabalho manual [...] Se se quiser criar uma nova camada de intelectuais chegando às mais altas especializações, próprias de um grupo social que tradicionalmente não desenvolveu as aptidões adequadas, será preciso superar dificuldades inauditas (GRAMSCI, 1995, p. 138/139).
} 
Como se observa, Gramsci identifica a dimensão política da escola, considerando-a de fundamental importância na formação de intelectuais orgânicos - aqueles que organizam a cultura, as mentalidades, as concepções de mundo no sentido da conquista da hegemonia. E como cada classe elabora seus próprios intelectuais orgânicos, sua função político-social é a busca do consenso em torno de determinado projeto político e societário, diferentemente dos intelectuais tradicionais, que se supõem independentes em relação à divisão do poder na sociedade.

O princípio educativo elaborado por Gramsci orienta-se, fundamentalmente, para a formação de intelectuais orgânicos das classes trabalhadoras, com o objetivo de desenvolver uma concepção contra-hegemônica. Para isso, precisam passar por uma formação escolar que lhe garanta o acesso especial a cultura. Não se trata de uma cultura enciclopédica, mas a mais próxima da vida e situada na história, no intuito de lhes conferir autoconhecimento e ação política, elementos necessários para se produzir um novo consenso (COUTINHO, 1999). Esta é a função social e política da escola comprometida com a emancipação de homens e mulheres que vivem da venda da sua força de trabalho, cuja luta se processa na sociedade civil.

Para Gramsci, nas sociedades ocidentais de capitalismo avançados o poder (coerção) não se concentra exclusivamente no Estado, mas diluído naquilo que denominou de "aparelhos privados de hegemonia". E como todo aparelho de hegemonia, em disputa, a escola, ao mesmo tempo em que difunde a ideologia dominante com vistas à formação do consenso, pode também constituir-se em lócus de produção e difusão de contra-ideologias, desempenhando um papel importante na luta contra-hegemônica ao capital. Todavia, como já demonstramos, não é essa a função da escola capitalista, mas internalizar nos indivíduos os valores do capital a fim de legitimar a posição que lhes foi atribuída na hierarquia social, induzindo-o, através de condutas certas e expectativas adequadas, a um conformismo generalizado. Desse modo, as reformas propostas pelos defensores do capital não alteram as estruturas fundamentais da sociedade. São implementadas para formar o trabalhador requerido pela nova sociabilidade do capital e "remediar os piores efeitos da ordem reprodutiva capitalista sem, contudo, eliminar os seus fundamentos causais antagônicos e profundamente enraizados" (MÉSZAROS, 2005, p.26). A reforma do Ensino possui essa direção política e aprofundará a dualidade educacional, 


\section{Uma ponte para o presente sob os pilares do passado: a dualidade educacional brasileira}

Sendo o capitalismo fundado e retroalimentado na desigualdade econômica, política e social, expressão do antagonismo entre trabalho e capital, haveria interesse das classes dominantes-dirigentes brasileiras em criar escolas e percursos formativos iguais para os sujeitos de classes distintas? A resposta para esta questão leva-nos a entender a dualidade educacional como manifestação específica do modo de produção capitalista; produto e produtora das sociedades de classes, voltada para a manutenção das desigualdades existentes na sociedade e não para a sua superação.

A dualidade educacional defendia pelos teóricos (neo)liberais é de fácil constatação na história brasileira e se expressa na existência - durante décadas - de dois percursos formativos (formação propedêutica e formação profissional), com objetivos diferentes e sem que houvesse equivalência entre ambas formações, o que impedia os egressos da formação profissional de acesso ao Ensino Superior. Previstas para as classes "menos privilegiadas", conforme palavras do então Ministro da Educação, Gustavo Capanema, as escolas técnicas profissionalizantes destinavam-se a criar na moderna juventude brasileira um "exército de trabalho" para o "bem da nação" (MEC/SEEC, apud FREITAG, 2005, p. 91); razão pela qual a "Lei Orgânica", de 1942, manteve o impedimento dos egressos da formação profissional em nível médio de segundo ciclo de terem acesso ao Ensino Superior.

A plena equivalência dos cursos só ocorreu no início da década de 1960, por meio da primeira Lei de Diretrizes e Bases (LDB), Lei $n^{\circ}$ 4024/61. Esta, entretanto, não foi capaz de superar a dualidade educacional, posto que "continuaram a existir dois ramos distintos de ensino, voltados para necessidades bem definidas da divisão do trabalho, de modo a formar trabalhadores instrumentais e intelectuais através de diferentes projetos pedagógicos" (KUENZER,1998, p. 368). Dualidade esta, que adquiriu novos contornos nas décadas seguintes.

A começar pela Lei $n^{\circ} 5692 / 71$, que reorientou as diretrizes e bases da educação nacional e tornou a profissionalização compulsória no Ensino de Segundo Grau. Instituída no período da ditadura civil-militar, a finalidade não manifesta dos planejadores, segundo Cunha (2000), era desviar os filhos das camadas populares para o mercado de trabalho e conter seu acesso ao Ensino Superior, uma vez que os conteúdos cobrados no exame de acesso ao Ensino Superior 
eram ministrados apenas no primeiro ano daquela etapa da escolaridade, reservando os dois anos seguintes aos conteúdos da formação profissional. Mais uma vez se explicitava a legitimação de dois percursos formativos: de um lado, um tipo de formação destinado aos que produzem a vida e a riqueza da sociedade, usando sua força no trabalho predominantemente manual; e do outro, um tipo de formação destinada aos grupos e segmentos que dão orientação e direção à sociedade, e voltada para o trabalho predominantemente intelectual. Daí a razão das escolas privadas terem ignoradas por completo a política de profissionalização universal e compulsória no Segundo Grau, e prosseguiram na preparação de vestibulandos (CUNHA, 2017).

A redemocratização brasileira e o fortalecimento dos movimentos e organizações sociais na década de 1980 reacenderam as perspectivas de mudanças e a possibilidade de se construir a educação dos trabalhadores na perspectiva do pensamento histórico-crítico. As idéias de matrizes marxianas e gramscianas - como "formação integral", "educação unitária", "politecnica" e "trabalho como princípio educativo" -, disputaram o consenso durante a elaboração do texto dedicado à educação na nova Constituição e durante a elaboração da nova LDB (Lei n 9394/96). Entretanto, como salienta Barbosa (2017), a adoção do país a agenda neoliberal, iniciada no governo Fernando Collor de Mello e intensificada nos dois mandatos do governo Fernando Henrique Cardoso, desvelou mais uma vez o lugar reservado aos trabalhadores na ótica das classes dominantes-dirigentes brasileiras. A edição do Sistema Nacional de Educação Profissional em paralelo ao Sistema Nacional de Educação, empreendida pelo Decreto n. 2209/97, ratificou a dualidade da estrutura educacional brasileira ao separar os cursos de Ensino Médio de caráter geral e os cursos profissionais, suprimindo, inclusive, o Ensino Técnico integrado oferecido pelas escolas da rede federal.

Seguindo as orientações do Banco Mundial e demais agências multilaterais, a reforma da educação da década de 1990 objetivou formar o trabalhador de novo tipo requerido pela acumulação flexível - o novo paradigma de produção. E por ser o trabalho simples a maioria dos postos de trabalho aberto no país, mediante a função que o Brasil exerce no cenário internacional, os neoliberais consideram desperdício de recursos financeiros a oferta de educação científicatecnológica mais avançada para todos os brasileiros, devendo ser restrita a um pequeno número de trabalhadores que desempenharão o trabalho criativo, de concepção e elaboração. Revigora-se, 
assim, o pensamento de Smith, de oferecer para a maioria dos trabalhadores uma formação simplificada e de baixos custos, isto é, "rudimentos de leitura e escrita" necessários para participar da vida social e produtiva.

Ainda que a composição política e a coalizão de classes de sustentação dos governos de Lula da Silva e Dilma Roussef (2003-2016) tenham se orientado pela perspectiva do Projeto da Terceira Via (GIDDENS, 2005), sem confrontar a nossa especificidade de "capitalismo dependente" (FERNANDES, 1975), as classes trabalhadoras obtiveram relativo avanço na conquista/ampliação de direitos sociais. No campo educacional, os avanços se materializaram, entre outras ações, na revogação do Decreto 2208/97 por meio do Decreto no 5154/2004, que abriu caminho para uma nova política no Ensino Médio e Ensino Técnico, com ênfase no Ensino Técnico integrado (nas modalidades concomitante e subsequente), e consolidado pelas Diretrizes Curriculares Nacionais do Ensino Médio (DCNEM), de 2012, cuja proposição principal é a integração curricular em torno dos eixos da ciência, cultura, trabalho e tecnologia, tendo o trabalho como princípio educativo; na construção de novas universidades federais; no aumento de recursos para o Fundo de Financiamento Estudantil do Ensino Superior (FIES); na criação de programas destinados ao jovens e adultos, como o Programa de Integração da Educação Profissional Técnica de Nível Médio ao Ensino Médio na Modalidade de Educação de Jovens e Adultos (PROEJA).

As classes dominantes e dirigentes brasileiras, porém, não suportariam por muito tempo o avanço das conquistas dos trabalhadores, e após a perda de seu projeto político e societário nas urnas iniciaram o ataque contra os direitos sociais e trabalhistas recém conquistados, o que foi consolidado com o golpe parlamentar, jurídico, civil e midiático em abril de 2016. A partir de então, retoma-se a implementação do projeto neoliberal, apresentando a flexibilização, a privatização, o ajuste fiscal, a redução do Estado e o enxugamento dos gastos públicos (leia-se, redução com as políticas sociais: saúde, educação, profissionalização, cultura, segurança etc) como "a solução" para a retomada do crescimento econômico do país. Utilizando-se dos mesmos discursos de viés moralista do passado, os golpistas apontam a corrupção e a má administração do Estado como as causas principais da recessão econômica, identificando o déficit orçamentário 
procedente de um Estado considerado bastante paternalista na "concessão" de direitos. Afinal, na concepção dos capitalistas, direitos são custos e incide na redução de suas margens de lucros.

Assim como no passado, a educação não tem passado ilesa a este processo e uma nova reforma curricular para o Ensino Médio tem sido implantada, sendo a pedagogia das competências e habilidades apresentada como a necessária para a formação do novo tipo trabalhador requerido após a reestruturação produtiva e a reorganização do trabalho: o trabalhador polivalente, conformado a não ter direitos, adaptável as mudanças e submisso a nova sociabilidade capitalista. Pautada nas idéias da matriz (neo)liberal, a reforma do Ensino Médio empreende um verdadeiro retrocesso na educação, mesclando o projeto educacional defendido pela ditadura civil-militar (com a Lei n. 5692/71), e o modelo defendido na contrarreforma da década de 1990.

\section{A retomada da agenda neoliberal e a reforma do ensino médio no governo Temer}

A Medida Provisória $n^{\circ} 746 / 2016$ e transformada na Lei $n^{\circ} 13.415$, sancionada pelo presidente Michel Temer em 16 de fevereiro de 2017, estabelece um conjunto de novas diretrizes para o Ensino Médio. Determina a flexibilização do currículo sob o argumento de que o Ensino Médio é extenso, superficial e fragmentado, o que ocasiona o desinteresse dos estudantes, não favorece a aprendizagem e os induz a não desenvolverem suas competências e habilidades. Disso decorre o baixo desempenho em Língua Portuguesa e Matemática, conforme demonstram os resultados do Sistema de Avaliação da Educação Básica (SAEB) e do Programa Internacional de Avaliação de Alunos (PISA).

Os defensores da reforma ressaltam que alguns países obtiveram a melhora da qualidade de seus sistemas educacionais após abrir espaço para a diversificação de ofertas e escolhas por parte dos alunos, havendo uma parte obrigatória e outra não. Assim, em vez de uma estrutura curricular comum a todos os estudantes brasileiros, o novo desenho reserva $60 \%$ da carga horária para a Base Nacional Comum Curricular (BNCC), que definirá o conteúdo comum a ser apresentado a todos, e destina os demais $40 \%$ da carga horária aos conteúdos optativos, chamados de "itinerários formativos específicos" a serem definidos pelos sistemas de ensino, com ênfase nas seguintes áreas 
de conhecimento: Linguagens e suas Tecnologias; Matemática e suas Tecnologias; Ciências da Natureza e suas Tecnologias; Ciências Humanas e Sociais Aplicadas; Formação Técnica e Profissional.

Muitos aspectos do novo currículo têm sido alvo de críticas por parte de estudantes, educadores e entidades organizadas. A primeira dela refere-se à determinação de apenas Matemática, Língua Portuguesa e Inglês se constituírem disciplinas obrigatórias ao longo dos três anos, conjugada com o fim da obrigatoriedade da oferta das disciplinas de Artes, Educação Física, Filosofia e Sociologia - algo que foi sutilmente modificado durante a tramitação da Medida Provisória no Congresso Nacional, quando os parlamentares definiram que essas disciplinas devem ter "estudos e práticas" incluídos como obrigatórios na BNCC. Esta e cada escola é que determinarão as disciplinas obrigatórias em cada itinerário.

Outro objeto de crítica da Lei $n^{\circ}$ 13.415/2017 é a não obrigatoriedade das escolas oferecerem os cinco "itinerários formativos", mas ao menos uma área. E caso haja a oferta de todas, o que dificilmente ocorrerá devido à precária estrutura das redes de ensino do país, o estudante poderá optar por apenas uma área, conforme seu interesse. Ademais, a Lei confere um novo peso a formação técnica e profissional, garantindo, segundo o referido ministro, “a oportunidade de o jovem optar por uma formação técnica profissional dentro da carga horária do ensino regular" (BRASIL, 2016). Sob o argumento de que "menos de 17\% dos alunos que concluem o Ensino Médio acessam a educação superior, e que cerca de 10\% das matrículas estão na Educação Profissional”, retorna-se o espírito da política educacional discriminadora do período da ditadura civil-militar e do período de Fernando Henrique Cardoso, "reeditando a antiga concepção do Ensino Médio como preparação para o Ensino Superior para uns, e formação para o trabalho para outros" (CUNHA, 2017, p.379).

Acrescenta-se que a educação minimalista destinada aos jovens das classes trabalhadoras tende a se agravar mediante a autorização dos profissionais com "notório saber" de ministrar aula nos cursos de formação técnica e profissional, desde que os cursos estejam ligados às áreas de atuação desses profissionais, o que demonstra ser a especialização técnica e a aquisição de competências para a empregabilidade a preocupação principal da formação profissional proposta. Trata-se, portanto, das mesmas proposições das Diretrizes Curriculares Nacionais do Ensino Médio (DCNEM) elaboradas no final da década de 1990 e exaradas pelo Parecer nº 15/98, que afirmavam a necessidade de adequar a educação às mudanças no setor produtivo e preparar os jovens para a flexibilização das relações e do mercado de trabalho (FERRETI; SILVA, p. 391). 
A retomada do projeto educacional neoliberal no atual governo ocorre devido ao retorno das mesmas pessoas que ocuparam postos estratégicos no MEC durante o dois mandatos do governo tucano, a exemplo de Maria Helena Guimarães de Castro, atual secretária geral do MEC e que durante o governo de Fernando Henrique Cardoso ocupou a presidência do Instituto Nacional de Estudos e Pesquisas Educacionais (INEP). Como identifica Cunha (2017, p. 379), “é de sua autoria a concepção da Medida Provisória n⿳ 746/2016, evidenciada na separação entre o Ensino Técnico e o Ensino Médio, apartação dissimulada nos itinerários formativos específicos - quatro propedêuticos e um terminal".

Observa-se, assim, que a reforma proposta não ataca o problema do Ensino Médio na sua raiz. Visa a implementar o projeto de educação destinada as classes trabalhadoras, elaborado e disputado pela classe empresarial, trincheirada em organizações como o "Movimento Todos pela Educação": uma formação minimalista, instrumental e pragmática em detrimento de uma educação com a finalidade de promover a maturidade intelectual do educando, a autonomia e a luta contra a alienação, como defendem Marx e Gramsci. Daí o pouco investimento na formação (inicial e continuada) dos professores, as péssimas condições de infra-estrutura na maioria das escolas públicas, muitas das quais sem laboratórios de ciências, laboratórios de informática, quadras de esportes (decentes), bibliotecas, merenda digna, professores bem qualificados e bem remunerados. A reforma proposta pela Lei ${ }^{\circ}$ 13.415/2017 fundamenta-se em concepções que perpassam séculos, como demonstra o estudo dos clássicos da matriz liberal e neoliberal. Trata-se de uma ponte construída no presente sob os pilares do passado.

\section{Considerações Finais}

A proposta que orientou a escrita do presente texto visa a contribuir com o conjunto das reflexões acerca da reforma do Ensino Médio, ressaltando o espectro teórico que fundamenta as propostas de formação dos trabalhadores em disputa em torno da reforma. Conforme a LDB (1996), o Ensino Médio é a etapa final da educação básica que tem a finalidade de consolidar e aprofundar os conhecimentos adquiridos no Ensino Fundamental para prosseguimento dos estudos; preparar o educando para o trabalho e para a cidadania; desenvolver a autonomia intelectual e o pensamento crítico, por meio da articulação teoria e prática. Entretanto, como 
buscamos demonstrar, parece não ser este o objetivo perseguido pelos planejadores da reforma, mas adequar o Ensino Médio as demandas econômicas e de mercado. Ao criticar o currículo vigente, de que "não dialoga com a juventude, com o setor produtivo, tampouco com as demandas do século XXI", o que leva os "jovens de baixa renda a não verem sentido no que a escola ensina", as premissas da nova reforma alinham-se às idéias defendidas pelos intelectuais orgânicos do capital de matriz (neo)liberal, seguindo as recomendações do Banco Mundial, assim como ocorreu na reforma instituída no governo de Fernando Henrique Cardoso.

Contrapondo-se a perspectiva instrumental, os teóricos da matriz histórico-social propõem uma educação que atue com fins de transformar o trabalhador em um agente político, que pensa e age para modificar a si e o seu meio (FREIRE, 1980), uma vez que "cada homem transforma a si mesmo, se modifica na medida em que transforma e modifica todo o conjunto de relações do qual ele é o ponto central" (GRAMSCI, 1995, p.7). Uma educação materializada, por exemplo, nas experiências da Escola Politécnica Joaquim Venâncio e da Escola Florestan Fernandes, alicerçadas no compromisso ético-político da formação humana e integral, por meio da integração curricular em torno dos eixos da ciência, cultura, trabalho e tecnologia. Formação esta que, tendo o trabalho como princípio educativo, destina-se a promover nos jovens e adultos trabalhadores a compreensão crítica do trabalho e da sociedade, levando-os a uma ação política com vista à desalienação, a transformação social e prevalência dos interesses do trabalho em detrimento do capital.

\title{
WORK AND EDUCATION IN THE NEOLIBERALISM AND HISTORICAL SOCIAL THEORY: FUNDAMENTALS FOR REFLECTING CURRICULUM REFORM IN MIDDLE SCHOOL
}

\begin{abstract}
This article aims to identify the main aspects of two proposals for the formation of the working classes, radically opposed theoretically and methodologically: the liberal matrix, based on the ideas of Adam Smith and Friedrich Hayek; and the historical-social matrix, based on the ideas of Karl Marx and Antonio Gramsci. It is a historical and bibliographical research, with the purpose of demonstrating the conservatism of the Temer government's discourse, which attempts to present as "new" the changes made in High School, through Law n 13.415 / 2017. The study demonstrates that the new curriculum design serves old interests: to reinforce the historical structural duality of Brazilian education, retaking the instrumental and fragmented formation,
\end{abstract}


proposed in Law 5692/71, of the period of the civil-military dictatorship, and in Decree $\mathrm{n}^{\circ}$ 2208/97, edited under the government of Fernando Henrique Cardoso. It concludes that, with the resumption of the neoliberal agenda, reform planners seek to adapt high school to economic and market demands, abandoning the project of human and integral formation, defended by theorists of the historical-social matrix and present in the National Curricular Guidelines (2012). In addition to abandoning the objectives set forth in the LDB (1996) for High School, among them, to develop the students' intellectual autonomy and critical thinking, through the articulation of theory and practice.

Keywords: Work. Education. Neoliberalism. Historical-Social Theory. High School.

\section{Referências}

ARANHA, M.L.A. História da Educação. São Paulo: Moderna, 1989.

BARBOSA, C. S. A política neoliberal e a contrarreforma na educação dos trabalhadores no governo Fernando Henrique Cardoso. Revista Educação em Debate, Fortaleza, ano 39, nº 74 , p.35-50, jul./dez. 2017.

BRASIL. Medida Provisória 746/2016. Brasília, 22 set. 2016. Disponível em: <http://www.planalto.gov.br/ccivil_03/_ato2015-2018/2016/Mpv/mpv746.htm>. Acesso em: 15 abril 2017.

COUTINHO, C. N. A época neoliberal: revolução passiva ou contra-reforma? Novos Rumos, Marília, v.49, n.1, p. 117-126, Jan-Jun, 2012

Brasileira, 1999.

Gramsci: Um estudo sobre seu pensamento político. Rio de Janeiro: Civilização

CUNHA, L. A. Ensino Médio: atalho para o passado. Educação e Sociedade, Campinas, v.38, n o 139, p. 373-384, abr-jun, 2017.

. O ensino profissional na irradiação do industrialismo. São Paulo: UNESP, Brasília, DF: Flacso, 2000.

FERNANDES, F. Capitalismo dependente e classes sociais na América Latina. $2^{\mathrm{a}}$ edição. Rio de Janeiro: Zahar, 1975.

FERREIRA, E. B. A contrarreforma do ensino médio no contexto da nova ordem e progresso. Educação e Sociedade, Campinas, v.38, n ${ }^{\circ}$ 139, p. 293-308, abr-jun, 2017. 
FERRETI, C. J.; SILVA. M. R. Reforma do ensino médio no contexto da medida provisória $\mathrm{n}^{\mathrm{o}}$ 746/2016: estado, currículo e disputas por hegemonia. Educação e Sociedade, Campinas, v.38, n o 139, p. 385-404, abr-jun, 2017.

FREIRE, P. Conscientização: teoria e prática da libertação. Uma introdução ao pensamento de Paulo Freire. $3^{\text {a }}$ ed., São Paulo: Editora Moraes, 1980.

FREITAG, B. Escola, Estado e Sociedade. $7^{\text {a }}$ ed., São Paulo: Centauro, 2005.

FRIGOTTO, G; MOTTA, V. Por que a urgência da reforma do ensino médio? Medida provisória $n^{\circ}$ 746/2016 (Lei n 13.417/2017). Educação e Sociedade, Campinas, v.38, nº 139, p. 355-372, abr-jun, 2017.

FRIGOTTO, G. A dupla face do trabalho: criação e destruição da vida. In: FRIGOTTO, G.; CIAVATTA, M. (orgs.). A experiência do trabalho e a educação básica. Rio de Janeiro: DP\&A, 2002.

GIDDENS, A. A terceira via: reflexões sobre o impasse político atual e o futuro da socialdemocracia. $5^{\text {a }}$ edição. Rio de Janeiro/RJ: Record, 2005.

GRAMSCI, A. Os Intelectuais Orgânicos e a Organização da Cultura. 9a ed., Rio de Janeiro: Civilização Brasileira, 1995.

HAYEK, F. A. Os princípios de uma ordem social liberal. In: CRESPIGNY, A.; CRONIN, J. (orgs.) Ideologias políticas. Brasília: Editora da UnB, 1998.

HUNT, E. K.; SHERMAN, H. J. História do pensamento econômico. 20ª ed. Petrópolis: Vozes, 2001.

LUKÁCS, G. Para uma otologia do ser social. São Paulo: Boitempo Editorial, 2012.

KUENZER, A. Z. Trabalho e escola: a flexibilização do ensino médio no contexto do regime de acumulação flexível. Educação e Sociedade, Campinas, v.38, n ${ }^{\circ}$ 139, p. 385-404, abr-jun, 2017 , p. 331-354.

A reforma do ensino técnico no Brasil e suas conseqüências. In: Ensaio: avaliação e políticas públicas em educação. Rio de Janeiro: Fundação Cesgranrio, v. 6, n.20, julho/set., 1998

MANACORDA, M. Marx e a pedagogia moderna. São Paulo: Cortez, 1991.

. O Princípio Educativo em Gramsci. Porto Alegre: Artes Médicas, 1990.

MARX, Karl. O Capital: crítica da economia política. São Paulo: Cortez, 1983 
. Manuscritos econômico-filosóficos e outros textos escolhidos. São Paulo: Abril Cultural, Coleção Os Pensadores, $2^{a}$ ed., 1978.

MÉSZAROS, I. A educação para além do capital. São Paulo: Boitempo, 2005.

Para Além do Capital. Campinas/SP: Boitempo, 2002.

SMITH, A. Riqueza das nações: investigação sobre sua natureza e suas causas. Tradução João Baraúna. $2^{a}$ ed. São Paulo: Nova Cultural, 1985. 